\title{
perifèria
}

Número 16, junio 2012

revistes.uab.cat/periferia - www.periferia.name

\section{Análisis crítico de las perspectivas y recursos para la trata de personas con fines de explotación sexual en Barcelona}

\author{
Sandra Peixoto Santos- Universidad Autónoma de Barcelona ${ }^{1}$
}

\begin{abstract}
Resumen
En este artículo presento abordajes en relación a la intervención sobre el fenómeno de la trata de personas con fines de explotación sexual en Barcelona desde la perspectiva de los profesionales implicados en los diferentes recursos existentes. Primeramente, considero las diferencias entre trata y prostitución, noción de víctima y perspectiva de género, y la influencia de la globalización en el fenómeno. En seguida, presento el contraste de perspectivas de los profesionales entrevistados en relación a los siguientes tópicos: problemas asociados a la trata, dificultades para la intervención en el fenómeno, coordinación de entidades, recursos humanos/materiales y políticas gubernamentales. Como conclusión, presento las soluciones propuestas por estos informantes clave para la intervención sobre la trata de personas con fines de explotación sexual. Pretendo lograr una visión antropológica que promueva la reflexión individual sobre soluciones y nuevas medidas de actuación.
\end{abstract}

Palabras clave: Intervención, trata de personas con fines de explotación sexual, problemáticas, contraste de perspectivas, soluciones.

\begin{abstract}
This paper presents approaches in relation to the intervention on the phenomenon of trafficking in persons for the purposes of sexual exploitation in Barcelona from the perspective of professionals involved in the different resources. First, I consider differences between trafficking and prostitution, the notion of victim and gender perspective and the influence of globalization on the phenomenon. Next, I present contrasting perspectives of the professionals interviewed in relation to the following topics: problems associated with trafficking, difficulties to the intervention on the phenomenon, coordination of entities, human / material resources and government policies. As a conclusion, I present the solutions proposed by these key informants for the intervention on trafficking for the purposes of sexual exploitation. I intend to achieve an anthropological vision that promotes individual reflection on solutions and new measures.
\end{abstract}

Keywords: Intervention, trafficking for the purposes of sexual exploitation, issues, contrasting perspectives, solutions.

\footnotetext{
${ }^{1}$ Enviar correspondencia a: Sandra Peixoto Santos (sandrasantos.net@gmail.com)
} 


\section{perifèria}

Número 16, junio 2012

revistes.uab.cat/periferia - www.periferia.name

\section{Introducción}

En el presente artículo presento el resumen de la investigación realizada para la tesis del Máster en Investigación Etnográfica, Teoría Antropológica y Relaciones Interculturales de la Universidad Autónoma de Barcelona.

El estudio fue realizado en la ciudad de Barcelona durante el primer semestre del año 2011 y tuvo como objetivo general conocer la intervención sobre el fenómeno de la trata de personas con fines de explotación sexual en Barcelona desde la perspectiva de los profesionales implicados en los diferentes recursos existentes.

El enfoque dado al fenómeno está basado en el punto de vista de los profesionales que intervienen en el fenómeno a través de los mecanismos que se activan para proteger, prevenir y asistir a las víctimas. El análisis resulta en el contraste de las perspectivas de esos actores.

Para conocer el fenómeno y las diferentes perspectivas asociadas fue necesario obtener información proveniente del trabajo de campo: por un lado, acompañando, como observadora participante, un servicio de atención de la Administración pública que interviene directamente con mujeres que ejercen la prostitución en las calles de Barcelona; por otro lado, se realizaron diez entrevistas semidirigidas a profesionales que intervienen en el fenómeno de la trata en Barcelona. La unidad de análisis fue constituida por los profesionales de las entidades sociales tanto de la Administración como de ONG que intervienen con las personas que ejercen la prostitución y/o con víctimas de trata con fines de explotación sexual y por los profesionales del cuerpo de seguridad que trabajan directamente con la problemática de la trata de personas con fines de explotación sexual.

Las profesiones y cargos ocupados en las entidades de los profesionales entrevistados son los siguientes:

Entidad Social 1: 1 coordinadora (trabajadora social) + 1 educadora (psicóloga)

Entidad Social 2: 1 coordinadora (jurista) +1 vicepresidenta (pediatra)

Entidad Social 3: 1 técnica de movilización social (trabajadora social) 


\section{perifèria}

Número 16, junio 2012

revistes.uab.cat/periferia - www.periferia.name

Entidad Social 4: 1 coordinadora (trabajadora social y pedagoga)

Entidad Social 5: 1 mediadora intercultural (traducción, mediación y agente comunitario de salud)

Entidad Social 6: entrevista conjunta con 1 investigadora (antropóloga) e 1 investigador (psicólogo y psicoanalista)

Entidad Social 7: 1 investigador (sociólogo)

Policía: 1 inspector

Se presentan las opiniones y percepciones de los que están trabajando en la problemática de la trata de personas con fines de explotación sexual y una visión antropológica que promueve la reflexión sobre soluciones y nuevas medidas de actuación.

\subsection{Diferencias entre trata y prostitución}

De forma muy simplificada, podemos entender la prostitución como el acto de ofrecer servicios sexuales a cambio de dinero. Sin embargo, esta transacción comporta una serie de estigmas, perspectivas y posiciones.

Para comenzar, hay que entender las perspectivas que existen cuando se habla de prostitución porque, como refiere Osborne (2004:31), "la perspectiva que se maneje condiciona la forma de aproximación legal a la prostitución".

Desde las perspectivas legales existe el prohibicionismo, el abolicionismo y el reglamentarismo y recientemente surgió la perspectiva basada en el modelo laboral.

Las prohibicionistas condenan legalmente tanto la prostitución como el lucro con el comercio sexual de otras personas. Las reglamentaristas consideran la prostitución como un mal inevitable y como tal se deberá legalizar a las prostitutas y los establecimientos del sexo dentro de unas áreas restringidas, la llamada zonificación. Pero esta reglamentación no ofrece ningún tipo de derecho laboral. Las 


\section{perifèria \\ Número 16, junio 2012 \\ revistes.uab.cat/periferia - www.periferia.name}

abolicionistas consideran la prostitución como una violación de los derechos humanos, como una actividad esencialmente violenta en que la persona es considerada siempre una víctima, un objeto. No tiene posibilidad de consentir, de desearlo, porque ha sido coaccionada. Finalmente, la perspectiva basada en el modelo laboral que enfoca la prostitución como un trabajo y como tal deberá gozar de todos los derechos legales como cualquier otro trabajador. (Osborne, 2004:3134)

Las dos últimas posiciones fueron las que han estado presentes en las negociaciones para el «Protocolo para prevenir, suprimir y sancionar a la trata de personas, especialmente mujeres y niños» como nos cuenta Doezema (2004) que ha estado involucrada en los debates como grupo de presión feminista. Básicamente, había dos grupos de presión feminista que no estaban de acuerdo con la posición relativa a la prostitución y los debates giraron en torno del consentimiento de una persona en decidir voluntariamente dedicarse a la prostitución. Esto ha influenciado la definición de tráfico, pues si para el grupo CATW (Coalition Against the Trafficking in Women) ${ }^{2}$ no hay posibilidad de consentimiento porque es siempre violación de los derechos humanos, no depende del engaño o fuerza porque es siempre esclavitud sexual. Para el grupo The Human Rights Caucus ${ }^{3}$, la fuerza o el engaño son condiciones necesarias en la definición de tráfico, pues justifican que una persona adulta puede consentir trabajar en una actividad ilegal como en la prostitución pero no en consentir ser secuestrado o realizar trabajos forzados. (Doezema, 2004:153)

Kempadoo (2005:58) hace la distinción de estas dos posiciones nombrándolas de feminismo radical a las que conectan inevitablemente la prostitución con el tráfico, pues la mujer es siempre una víctima. Por otro lado, nombra feminismo trasnacional el abordaje de la prostitución como una opción de las mujeres que tienen capacidad de elegir, de negociar y de consentir.

\footnotetext{
${ }^{2}$ CATW es una organización no gubernamental que promueve los derechos humanos de las mujeres, trabajando a nivel internacional para combatir la explotación sexual en todas sus formas.

3 Actualmente Tom Lantos Human Rights Commission es un comité bipartidista de la Cámara de Representantes de Estados Unidos. Su misión declarada es "promover, defender y abogar por normas internacionalmente reconocidas de derechos humanos de una manera no partidista, tanto dentro como fuera del Congreso, tal como se consagra en la Declaración Universal de los Derechos Humanos y otros instrumentos pertinentes de derechos humanos".
} 


\section{perifèria}

Número 16, junio 2012

revistes.uab.cat/periferia - www.periferia.name

De los debates anteriormente referidos salió en el año 2000 el «Protocolo para prevenir, suprimir y sancionar a la trata de personas, especialmente mujeres y niños», más conocido como Protocolo de Palermo, firmado por más de ochenta países como un instrumento de las Naciones Unidas para luchar contra el tráfico de personas. Hay que poner de relieve que la fuerza y la coacción fueran integradas para definir tráfico, pero al mismo tiempo fue considerado que si es usada la fuerza, el consentimiento no es verdadero. Así que, los dos grupos de presión se sintieron vitoreados con el referido protocolo. (Ausserer, 2007:43)

Es importante toda esta reflexión en torno del consentimiento pues como nos advierte Piscitelli (2006:50) es lo que establece la frontera entre prostitución forzada y voluntaria. Es a partir de aquí, de la voluntariedad o no de ejercer la prostitución, que nace la trata de personas con fines de explotación sexual. Es partiendo de la no voluntariedad, del ser forzado, que se puede asociar a la idea de esclavitud y de redes de crimen organizado.

Puesto esto, podemos inferir que en el caso de la trata de seres humanos con fines de explotación sexual, no es que la persona decida ejercer la actividad de la prostitución, independiente de sus motivaciones personales, de la cuestión moral y de las posiciones teóricas o legales. La cuestión aquí es que la persona está siendo obligada a ejercer la prostitución contra su voluntad o que ha aceptado ejercer la prostitución pero en condiciones que no ha podido elegir.

Esquematizando la cuestión de la prostitución y de la trata de personas con fines de explotación sexual ${ }^{4}$ :

\footnotetext{
${ }^{4}$ En el esquema se considera como explotación la referida en el Protocolo de Palermo (Protocolo para prevenir, reprimir y sancionar la trata de personas, especialmente mujeres y niños, que complementa la Convención de las Naciones Unidas contra la Delincuencia Organizada Transnacional): "la explotación de la prostitución ajena u otras formas de explotación sexual, los trabajos o servicios forzados, la esclavitud o las prácticas análogas a la esclavitud, la servidumbre o la extracción de órganos".
} 


\section{perifèria}

Número 16, junio 2012

revistes.uab.cat/periferia - www.periferia.name

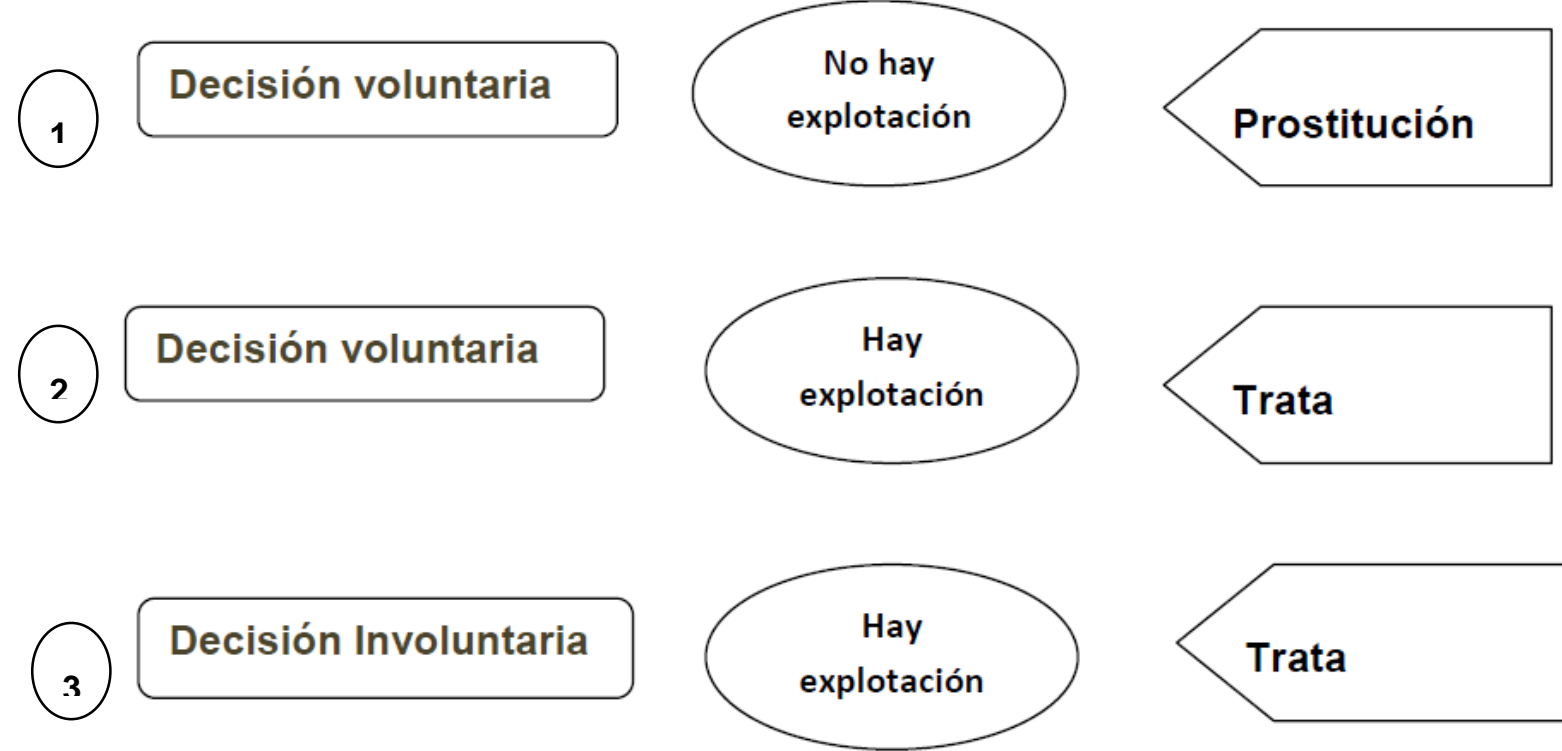

Fig. 1. Esquema de diferenciación entre trata y prostitución. Elaboración propia.

Me gustaría resaltar que, aunque en este esquema de diferenciación de prostitución y trata esté basado en la capacidad de decisión voluntaria o no para ejercer la prostitución, hay que tener en cuenta las condiciones que llevan una persona a tomar esa decisión, aunque voluntaria. Es posible que sea motivada por desigualdades sociales, falta de oportunidades, situaciones de miseria y pobreza. (Santos, 2009:23)

Siguiendo la misma idea, Piscitelli (2006:50) en el estudio que realizó sobre mujeres brasileñas que vienen para España para ejercer la prostitución también designa la noción de vulnerabilidad como el factor causal de la elección del trabajo sexual a través de la migración ilegal como resultado de la ausencia de expectativas de una vida mejor en el país de origen.

Por otro lado, Agustín (2006:75) contrasta este argumento defendiendo que la idea de que uno migra porque no tiene condiciones en el país de origen no es válida para todas las personas inmigrantes, pues no todos los pobres deciden emigrar.

Juliano (2004:49) aclara que la libertad de elección deberá ser contextualizada 


\section{perifèria}

Número 16, junio 2012

revistes.uab.cat/periferia - www.periferia.name

entendiendo lo que hay detrás y según los límites históricos y culturales para cada persona según su sexo.

Entendiendo, de esta forma, la prostitución vinculada al poder de decisión de la persona podemos diferenciar cuando es prostitución y cuando es trata de personas con fines de explotación sexual. La prostitución puede existir sin la trata pero la trata no puede existir sin la prostitución porque es a través de ella que se materializa y subsiste. Por otro lado, también es importante entender cuando hay o no explotación.

\subsection{Usos y abusos del concepto de "víctima" y la perspectiva de género en la trata de seres humanos con fines de explotación sexual}

De la postura del feminismo radical sale la idea de que toda mujer que ejerce la prostitución es una víctima, porque está sufriendo los designios del patriarcado, del poder del hombre sobre la mujer: "Neste sentido, este discurso constrói um sujeito reduzido à sujeição à própria opressão". (Ausserer, 2007:92)

Esta es una postura que es rechazada, en general, por los estudios feministas por representar una mujer pasiva frente al patriarcado y a las estructuras que la oprimen (Santos, 2009:74). Sin embargo, aunque no se utilice el término de víctima para toda la mujer que ejerce la prostitución, dice Agustín (2001: 548) que esta posición reduccionista existe porque se está hablando de la industria del sexo y de mujeres inmigrantes. Defiende que el hecho de que se victimice a mujeres extranjeras está conectado a la discriminación social y de género. Porque se está suponiendo que no tienen la debida responsabilidad y capacidad para emigrar y buscar trabajo, el trabajo que elijan. También Stolcke (2000:28) sugiere que la mujer es objeto de desigualdad social solamente por el hecho de ser mujer, en contextos históricos específicos.

En relación a la inmigración, Sassen (2002:7) defiende que el hecho de que las políticas inmigratorias sean tan represivas y controladoras hacen que las mujeres usen a traficantes para el cruce de la frontera y resulta que éstos pueden pertenecer a redes criminales vinculadas a la industria del sexo. Entonces, de un inmigrante ilegal puede surgir una víctima de explotación sexual. Además, esto

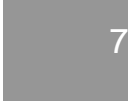




\section{perifèria}

Número 16, junio 2012

revistes.uab.cat/periferia - www.periferia.name

conlleva que la mujer sea más vulnerable y que no recurra a la ley por su situación ilegal.

En esta línea, Maqueda (2007:16) denuncia el enfoque dado por parte de la legislación que en vez de proteger las verdaderas víctimas de explotación sexual está direccionado al control del tráfico de inmigrantes ilegales.

En relación al concepto de explotación para las relaciones sexuales remuneradas, Agustín (2001:539) señala las diferencias que existen entre la trabajadora del sexo que tiene capacidad de negociación (con la clientela y los empresarios e intermediarios) y la que se encuentra en posición subordinada y con su capacidad de acción claramente limitada. Maqueda (2007:15) advierte la ambigüedad del concepto pues puede sugerir cualquier cosa:

... desde un genérico afán de enriquecimiento hasta la idea de abuso en las condiciones de contratación o de prestación del trabajo sexual.

Hay que tener en cuenta que esta concepción de la mujer que ejerce la prostitución como víctima es peligrosa en el sentido de que está descartando las herramientas de las mujeres para actuar y muchas veces incluso para que sean ellas mismas las explotadoras, como sustenta Osborne (2009:7) afirmando que las mujeres también son violentas, tanto física como psicológicamente.

En este sentido, Doezema (2004:159) crítica la postura de mujer como víctima cuando se equipara la mujer a los niños de acuerdo con la propia denominación del Protocolo de Palermo que afirma "especialmente para mujeres y niños". La nombra como una infantilización de la mujer que justifica una serie de proteccionismos desmedidos.

Es clara la posibilidad de hacer un análisis de género pues lo que el titulo del Protocolo nos dice es: ¿las mujeres y los niños son más vulnerables que los hombres?, ¿las mujeres son comparables a los niños mientras que los hombres, no?, ¿los hombres no son susceptibles de ser "tratados" pero las mujeres sí?

El interés de utilizar el concepto de víctima en relación a la trata de personas con fines de explotación sexual también es referido por Kempadoo (2005:67) como la

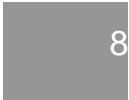




\section{perifèria}

Número 16, junio 2012

revistes.uab.cat/periferia - www.periferia.name

obligación de la denuncia para que la víctima, que es realmente víctima en el sentido de estar siendo explotada y abusada, tenga protección.

Finalmente, Piscitelli (2006:14) resume las posiciones donde los demás sitúan a las mujeres que venden el sexo: o son sumisas (víctimas, esclavas sexuales, sin poder) o subvertidas (con poder, autonomía pero con ganancias de sexo y dinero).

Esta idea puede ser contrastada con la de Juliano (2004:43) defendiendo que el estigma divide las mujeres en buenas y malas y cómo influye el género en esta concepción: si fueran hombres los trabajadores sexuales la valoración dada a la actividad sexual pagada sería diferente tal como la proyección de estigmas.

Visiblemente entramos ahora, ya no en la cuestión de la mujer como víctima, pero en entender el porqué de ser siempre la mujer la víctima y cómo cambiaría si hablamos de hombres.

Agustín (2006:78) plantea la reflexión de cambiar la situación e imaginar que son hombres en grandes números a la vez de mujeres y cómo se lo miraría: "¿Se consideraría tal estrategia como tragedia, o más bien como acto pragmático e incluso creativo?"

Rubin (1996:76) explica que "el género es una división de los sexos socialmente impuesta. Es un producto de las relaciones sociales de sexualidad." Advierte la autora que el hecho de existir la división del trabajo por sexos es lo que divide hombres de mujeres y su igualdad, exacerbando las diferencias biológicas y creando el género.

Podemos entonces inferir que solamente existe el concepto género como creación humana porque también existen desigualdades entre hombres y mujeres fruto de la misma creación humana. Y la trata de personas con fines de explotación sexual es otra de las creaciones basadas en género.

\section{3 ¿En qué ha influenciado la globalización en la trata de seres humanos con fines de explotación sexual?}

Autores como Giddens (2000) o Santos (1999) apuntan que la globalización es un 


\section{perifèria \\ Número 16, junio 2012 \\ revistes.uab.cat/periferia - www.periferia.name}

fenómeno complejo de difícil definición y que engloba además de la dimensión económica, en cuyas definiciones se suelen centrar, las dimensiones sociales, políticas y culturales. Ambos relacionan la globalización con las relaciones sociales, con dependencia mutua, creando un juego de ganadores y perdedores. Este juego está claro en la trata de seres humanos con fines de explotación social. El que tiene el poder, coacciona, engaña, abusa, explota al sumiso que tiene que acatar sus órdenes por la situación de vulnerabilidad en que se encuentra.

Aprovechando estas dinámicas surgen las redes de crimen organizado trasnacionales cuyo objetivo es la acumulación de capital a través de diversos tipos de explotación. En el caso de la trata con fines sexuales, explotación de las personas por medio de servicios sexuales.

Con el aumento de los circuitos globales, las desigualdades e injusticias siguen paralelamente ese aumento. El desequilibrio de la distribución de la riqueza y de las oportunidades es claro entre los Ilamados países del Norte y del Sur.

Es en contextos desiguales que las personas perdedoras tienen que encontrar formas de ganarse la vida. Es en contextos desiguales que la explotación sobrevive, tiene que sobrevivir para mantener el sistema capitalista globalizado.

La decisión de ejercer la prostitución supone realizar una actividad ilegal en la mayoría de los países y como tal engloba la entrada en el mundo ilegal. Como consecuencia, hay la posibilidad de acceso a redes de crimen organizado que conlleva la trata. La situación empeora cuando a través de la globalización estas redes de crimen organizado que antes eran territoriales han podido expandir sus negocios fuera de las fronteras. Entonces se ha creado el crimen trasnacional. (Favaro, 2008)?

Otra de las situaciones que la globalización ha venido a promover fue el crecimiento de migración. El mundo ha cambiado, lo que tardaba meses, ahora tarda horas; lo que era lejos, ahora es cerca. No sería un problema si este flujo fuera equilibrado; sin embargo, son las personas más desfavorecidas las que buscan en la inmigración nuevas posibilidades de una vida mejor. Surge entonces la necesidad de controlar las fronteras de los Estados y como consecuencia germinan las inmigraciones 


\section{perifèria}

Número 16, junio 2012

revistes.uab.cat/periferia - www.periferia.name

ilegales. Estas dan poder a las redes de crimen organizado para "facilitar" la entrada del inmigrante en el país de destino. Por otro lado, estas redes se aprovechan para proceder a la explotación de la persona una vez que ésta se encuentra en otro país, muchas veces de idioma distinto al suyo, sin nadie conocido, en una nueva cultura muchas veces muy distinta a la suya, con miedo y en completa situación de vulnerabilidad. Para Ary (2009:50) "o abismo existente entre as condições de vida e trabalho nos países de origem e de destino destes deslocamentos humanos consubstanciam-se como essenciais para uma compreensão ampla acerca deste processo."

Finalmente, el otro lado de la cuestión es que, justamente, porque muchas de las víctimas de trata con fines de explotación sexual son inmigrantes ilegales ésta sea la justificación para no realizar la denuncia de su situación a las fuerzas de seguridad. Por un lado, tienen miedo de los captadores que las mantienen en un enmarañado de amenazas $y$, por otro, tienen miedo a la expulsión. (Kempadoo, 2005:69)

La globalización no es el problema, el problema es lo que el ser humano hizo y sigue haciendo con la globalización. Ha promovido las desigualdades, vulnerabilidades y falta de oportunidades.

\section{El contraste de perspectivas de los diferentes profesionales: puntos comunes y contradictorios}

\subsection{Problemas asociados a la trata}

La globalización económica de los 80 dio paso a la expansión extraordinaria de una industria prostitucional.

Uno de los problemas referidos por uno de los entrevistados de una ONG fue la importancia de la globalización económica de los 80 . Según éste, esto fue lo que dio paso a la expansión extraordinaria de una industria prostitucional que funciona con dos movimientos simultáneos: por el lado de la oferta y por el lado de la demanda. Por el lado de la oferta, refería una matriz que funciona al lado de las organizaciones, que es la expansión de los grupos que han visualizado aquí un espacio de acumulación económica a escala global. Y por el lado de la demanda, 


\section{perifèria}

Número 16, junio 2012

revistes.uab.cat/periferia - www.periferia.name

refiere que hubo la reconstrucción de una práctica sociocultural sexual, un cambio cultural que ha fomentando el consumo de la prostitución en los países occidentales.

Si juntamos el cambio del movimiento de oferta de servicio prostitucional con las demandas y la tolerancia por parte de la sociedad, referido por otra de las entrevistadas de otra ONG, puede que nos acerquemos a las raíces sociales para el crecimiento del fenómeno de la trata de personas con fines de explotación sexual. Lo que nos están alertando estos profesionales es que la conjetura de la industria prostitucional al haber crecido, ha fomentado la visión de negocio con la prostitución y respectiva explotación sexual. Para obtener lucros se añadió el engaño y la coacción a personas que de antemano tienen un perfil más vulnerable.

\section{La falta de oportunidades como factor determinante}

Analizando las aportaciones de los profesionales en relación a la falta de oportunidades, se entiende que determinan, por un lado, la toma de decisión para ejercer la prostitución y, por otro lado, la vulnerabilidad para el reclutamiento para una situación de trata con fines de explotación sexual.

El perfil de las víctimas indicado por el inspector policial confirma esta premisa:

-Son reclutadas en países con dificultades económicas, de los estratos sociales más bajos y con escaso "nivel cultural" (formación académica).

-Suelen ser jóvenes (horquilla de edad entre 15-25 años), con familiares a su cargo, problemática familiar (p. ej. antecedentes de maltrato), engaño (total o parcial), abuso de situación de necesidad o vulnerabilidad... ${ }^{5}$

Del lado de los cuerpos de seguridad nunca se considera que haya consentimiento en la trata porque es un consentimiento viciado. Para la policía en las situaciones de trata hay un engaño parcial, en el sentido que los reclutadores o proxenetas utilizan las siguientes mentiras/ilusiones para engañar: ${ }^{6}$

\footnotetext{
5 Entrevista semidirigida no5 realizada el 21-04-11
}

${ }^{6}$ Entrevista semidirigida no 5 realizada el 21-04-11 


\section{perifèria}

Número 16, junio 2012

revistes.uab.cat/periferia - www.periferia.name

-"Vas a ganar mucho dinero"

-Uso del apego afectivo de la víctima al proxeneta para su posterior explotación pueden empezar a salir con la chica para que se enamore, pagan cenas en restaurantes de lujo, todo un entramado para convencer a la mujer a venir a España para ejercer la prostitución de forma "voluntaria" de forma que puedan tener un futuro juntos con hijos y sin problemas económicos.

-Cuando hay situaciones de vulnerabilidad de las mujeres, el engaño es usado con la ilusión de poder tener una vida mejor para la captación.

El tema del dinero también ha sido nombrado por los profesionales sociales como siendo transversal a la exposición a situaciones de explotación sexual y trata con propósitos sexuales, una vez que es lo que condiciona a cambiar su situación. La inexistencia de autonomía económica a corto plazo limita la toma de decisión o la recuperación y reinserción. También fue nombrado el hecho que muchas veces no se trata de una recuperación individual, pues incluye también otras personas: sus dependientes y de su entorno.

Es con esta visión de impotencia para solucionar determinadas situaciones que la mayoría de las entidades sociales opta por acercarse al colectivo en cuestión a través del tema sanitario, ya que es el recurso más accesible, mientras un recurso laboral o económico es mucho más complicado de facilitar. Es una estrategia para quizá lograr facilitar otros recursos. No obstante, ¿puede ser que la falta de oportunidades haga que el trabajo de los profesionales se direccione para lo que realmente es posible, un servicio para que cuiden su salud? El cuidado sanitario es de extrema importancia, pero no suficiente. Parece que la situación ideal sería lograr asociar esta vía de entrada complementada con otros recursos que permitiesen otras oportunidades.

Es interesante girar el prisma y mirar ahora la cuestión económica desde el otro lado. También fue nombrado el dinero, por una profesional de ONG, pero del lado 


\section{perifèria \\ Número 16, junio 2012 \\ revistes.uab.cat/periferia - www.periferia.name}

de los grupos explotadores que dan vida al fenómeno de la trata de personas con fines de explotación sexual. Esta perspectiva suporta el problema desde una visión menos asistencialista sino más preventiva y punitiva.

\section{El miedo como factor limitante}

El miedo de las víctimas a los miembros de la organización fue nombrado como factor que condiciona una posible denuncia. El hecho de que existan amenazas, agresiones y deudas económicas atrapa las personas tratadas en la red. También fue comentado que el miedo es tanto hacia su persona como a la de sus familiares pues en sus países de origen residen traficantes y captadores. Por otro lado, algunas personas son provenientes de países donde la cultura determina la desconfianza a la policía y este esquema es reproducido en otros países, condicionando su reconocimiento como ciudadanas detentoras de derechos.

\section{Algunos métodos de actuación por parte de la sociedad promueven el fenómeno}

Entendiendo, en este caso, la sociedad como todo el conjunto de individuos y sus diferentes comportamientos, acciones y percepciones que influyen en el fenómeno de la trata con fines de explotación sexual. Hay varios puntos comentados por los profesionales entrevistados:

- Los agentes sociales e institucionales infantilizan las víctimas de trata.

- Se pierde mucha de la riqueza de los procesos porque se pretende que las víctimas pasen integralmente de un mundo al otro.

- Algunas de las víctimas pasan a controladoras dificultando los procesos de identificación.

- La policía en las redadas hace la clasificación de las que consideran víctimas de las "controladoras", sin consultar a los equipos de primera línea. ¿Qué criterios de clasificación son usados?

- El fenómeno es oculto (pisos, clubs) dificultando la intervención de agentes sociales y policiales.

- La legislación no es suficientemente adecuada para toda la problemática.

- Los medios de comunicación no visibilizan los casos personales de empoderamiento de las víctimas.

- El estigma asociado a la prostitución limita las acciones contra la trata.

- El Síndrome de Estocolmo hace que la víctima no se reconozca como víctima.

- La diferencia entre trata y tráfico muchas veces no es clara dificultando las intervenciones.

- Se ha gastado mucha energía en posicionamientos teóricos y políticos improductivos. 


\section{perifèria \\ Número 16, junio 2012 \\ revistes.uab.cat/periferia - www.periferia.name}

- Las víctimas de trata con fines de explotación sexual se sienten culpadas por el trabajo sexual lo que condiciona su proceso de recuperación.

- La explotación sexual deja secuelas que limitan la reconstrucción de una nueva vida.

- Falta entender el fenómeno desde las personas tratadas.

\section{Las organizaciones criminales tienen métodos de actuación muy eficaces}

Otro de los problemas asociados a la trata es que las redes criminales desarrollan medidas más eficaces de actuar que los agentes de intervención.

El propio inspector policial entrevistado también reconoció este ingenio de las redes criminales como un problema para la actuación de los cuerpos de seguridad, que desgraciadamente suelen ir por detrás.

\section{Problemas asociados a la trata de menores}

Se separa la trata de menores de la de adultos

Según los profesionales de la entidad social que trabaja directamente con la trata de menores con fines de explotación sexual, uno de los problemas existentes es la separación entre menores y adultos porque esto conlleva la deficiente identificación de menores tratados ya que los procedimientos son diferentes.

Se está conculcando un derecho humano - la identificación a algunos menores

Otro de los problemas fundamentales marcados para menores es la cuestión de la documentación que para algunos no se les reconoce. Se presume que falta un trabajo de asegurarse la veracidad de los registros de filiación por parte de las emisiones de visados y pasaportes.

El gran problema es que los niños sin documentación están más expuestos a la trata, pues si "no existen", son presas fáciles para funcionar como mercancía y respectiva explotación.

Las casas de acogida de menores no están especializadas para el acompañamiento de menores víctimas de trata sexual

Otra de las problemáticas asociadas a los menores es la falta de recursos especializados para atender a menores tratados identificados. Según el inspector 


\section{perifèria}

Número 16, junio 2012

revistes.uab.cat/periferia - www.periferia.name

policial, ya ha habido casos de enviar menores al recurso asistencial para víctimas de trata con fines de explotación sexual - "Programa SICAR. CAT", porque es más apto para prestar el acompañamiento de un menor tratado que las casas de acogida para menores que están direccionadas para otras problemáticas relacionadas con menores, no la de la trata de menores con fines de explotación sexual.

\subsection{Dificultades para la intervención en el fenómeno}

Falta formación específica sobre la trata de personas con fines de explotación sexual para los profesionales

Las dificultades apuntadas por las profesionales sociales para intervenir con personas tratadas con fines de explotación sexual es la falta de formación de los profesionales que trabajan directamente con el colectivo. Sin embargo, otra de las profesionales advirtió que aunque falte dar formación a los profesionales, también faltan formadores específicos. También hay que tener en cuenta que los profesionales que no intervienen directamente con personas que ejercen la prostitución o con personas tratadas, deberían tener formación específica; en particular, en la identificación de víctimas y circuitos existentes de acompañamiento y protección.

El problema de la identificación: "Las víctimas no se reconocen"

La mayoría de los entrevistados estaba de acuerdo con el problema de la identificación de las víctimas y han apuntado varios factores influyentes en esa identificación:

-Es un colectivo invisible.

-El vínculo con el explotador condiciona el propio reconocimiento de la víctima:

-Los profesionales tienen dificultad en intervenir porque las víctimas no se reconocen como tales.

La denuncia como factor determinante para la intervención 


\section{perifèria}

Número 16, junio 2012

revistes.uab.cat/periferia - www.periferia.name

La intervención de las entidades para personas que están siendo tratadas con fines de explotación sexual está condicionada por la existencia de denuncia por parte de la víctima:

Persona Tratada que NO denuncia

Persona tratada que denuncia

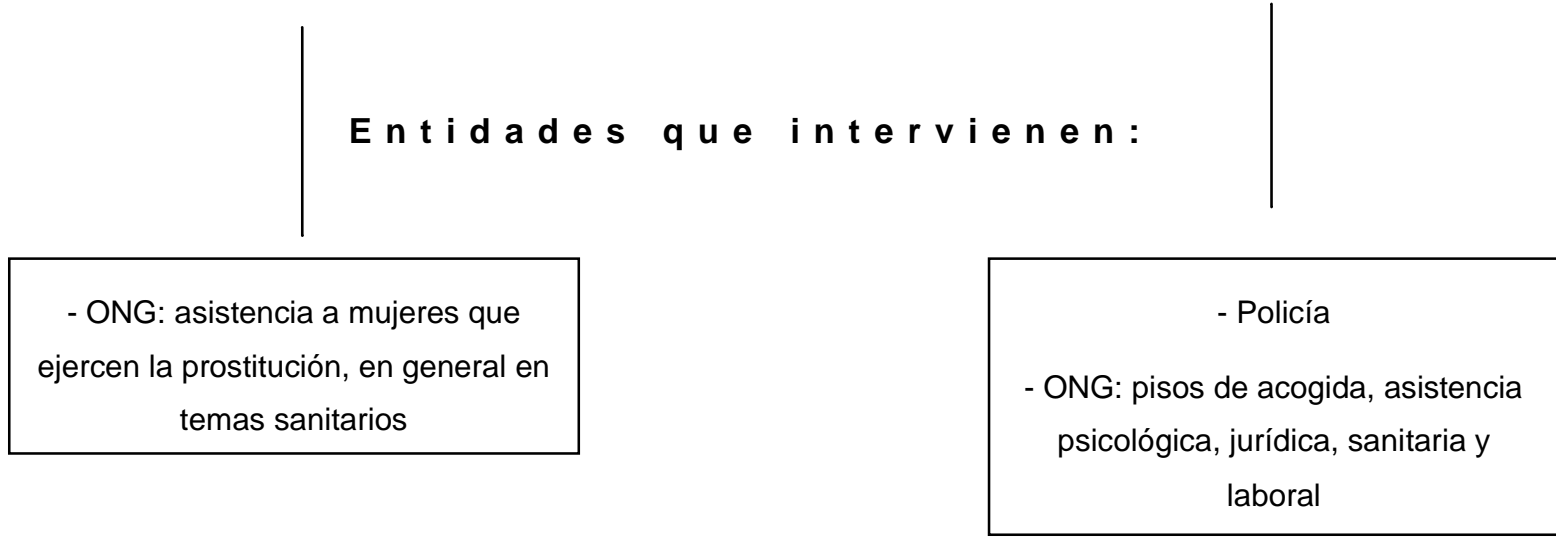

Fig. 2. Esquema de funcionamiento de las entidades según la existencia de denuncia por parte de las personas tratadas. Elaboración propia.

También fue apuntada por una profesional social la dificultad de obtener una denuncia por parte de la víctima. El hecho de que exista esta necesidad de denuncia, condiciona y limita la intervención de los profesionales.

En la misma línea, fue nombrado, en particular por el inspector policial, todo el problema alrededor de la obligación de que exista una denuncia para que se pueda avanzar con un proceso judicial.

En relación a esta cuestión de la denuncia por parte de víctima también fue apuntada otra dificultad: tema policial vs tema social. Mientras el social está preocupado con la asistencia y recuperación de la víctima, el policial pretende obtener la denuncia para detener a los causadores del delito. En consecuencia, hay diferentes objetivos por parte de las entidades una vez que la víctima denuncia su situación. 


\section{perifèria \\ Número 16, junio 2012 \\ revistes.uab.cat/periferia - www.periferia.name}

Sin embargo, cuando se realizó la entrevista con el inspector policial este resaltó el tema de la victimización secundaria como algo que tienen bastante consciente y que se deberá evitar.

El acompañamiento psicosocial a la víctima es realizado por las ONG, una vez que la policía no tiene recursos propios para ese acompañamiento. Según el inspector, cuando hay un caso de trata, la policía entra en contacto con las ONG para activar el adecuado acompañamiento de las víctimas.

\section{La protección de la víctima después de la denuncia}

Una vez obtenida la denuncia por parte de la víctima, de nuevo encontramos otras dificultades para la intervención, hace sentido preguntar: ¿quién protege la víctima?, ¿cuáles son los mecanismos activos para el proceso de recuperación y rehabilitación de la víctima?

Cuestionando al inspector de la policía sobre la protección de las víctimas fue referida la ley del testigo protegido. Con esto se asegura el anonimato de la víctima denunciante. Es verdad que se asegura el anonimato de los datos personales de quien hace la denuncia pero la protección física de la víctima, ¿quién la hace?

Las dificultades estructurales asociadas a las regulaciones gubernamentales

Las entidades funcionan según disposiciones jerárquicas provenientes de regulaciones de los organismos pertenecientes a la Administración pública. Las ONG aunque parezcan independientes, dependen de subvenciones estatales para poder llevar a cabo sus proyectos de intervención. Si éstos no están de acuerdo con los objetivos y estrategias de actuación de las directrices gubernamentales, podrá estar condicionada la subvención y por supuesto la respectiva intervención.

A resaltar que fue también nombrada por una profesional de ONG entrevistada la cuestión de la conexión de la trata de personas con fines de explotación sexual con el tema de inmigración ilegal y la Ley de Extranjería. Esto constituye una dificultad para los que dedican su trabajo en la asistencia y protección a las víctimas, pues la condición de ilegal y el miedo a la expulsión pueden determinar el silencio de las 


\section{perifèria \\ Número 16, junio 2012 \\ revistes.uab.cat/periferia - www.periferia.name}

víctimas. Además, los propios profesionales también ven su trabajo condicionado como nos refiere otra de las entrevistadas que presta asistencia en la calle, explicando que muchas veces mientras realizan su trabajo la policía hace redadas de identificación, siendo un impedimento para los que prestan asistencia. Otra de las entrevistadas que pertenece a este grupo añadió la falta de coordinación entre las diferentes entidades como la primera dificultad para ejercer su trabajo.

\section{Las dificultades de intervención con menores}

En relación a las menores víctimas de trata con fines de explotación sexual hemos visto que los mecanismos que se activan y la propia identificación son diferentes. Así que, en relación a las dificultades nombradas para intervenir fueran sobre todo a nivel de la identificación por parte de las entidades y la falta de disposiciones específicas para menores.

A nivel de intervención en trata con fines sexuales, una de las entrevistadas que trabaja directamente con esta temática defiende que tanto el Plan Nacional como los protocolos (ICD + ICDona) siempre son dirigidos a adultos. Reclama que no hay acciones específicas en materia de trata de menores. Explicaba que en su entidad se centran en que hay que tener intervenciones específicas con menores diferentes de las que se llevan a cabo con adultos y diferentes de las intervenciones que se llevan a cabo con menores que han podido sufrir otro tipo de maltratos a nivel familiar 0 en otro contexto completamente diferente, que no implica una explotación, además de la agresión sexual, una organización, un lucro, un transporte, una red que alimenta y que facilita esa explotación.

Formas de identificación de menores tratados

Según las profesionales de la ONG entrevistada, las formas de identificación de menores víctimas de trata con finalidades sexuales en Catalunya son a través de la documentación que posee en ese momento. Cuando es un menor que no tiene documentación y si se sospecha que tiene la minoría de edad se hacen pruebas osiométricas.

También explicaba que según la nueva Ley 14/2010 de Oportunidades y Derechos en la Infancia y Adolescencia, se plantea una presunción de minoría de edad. 


\section{perifèria \\ Número 16, junio 2012 \\ revistes.uab.cat/periferia - www.periferia.name}

Hasta que no se determina que hay mayoría de edad el menor entraría bajo el amparo de los organismos competentes en materia de protección y atención a infancia y adolescencia en riesgo que es la DGAIA - Dirección General de Atención a la Infancia y Adolescencia, que depende de la Generalitat de Catalunya.

Según dicen, no hay un único organismo competente en esta detección. Su sugerencia era que tendría que haber una corresponsabilidad entre fuerzas y cuerpos de seguridad del estado, Mossos d'Esquadra en Catalunya, servicios sociales, sanidad. Explicaba que, según su visión, habría primero que identificar a todos los agentes que contactan con la problemática para determinar niveles de responsabilidad en esta detección. Y luego poner en marcha una estrategia de prevención y sensibilización. A nivel de protección, reclamaba una adaptación y adecuación a la realidad de la problemática de los menores tratados. Finalmente, generar protocolos para detectar situaciones de alarma sería fundamental.

Formas de intervención de menores tratados

Según estas entrevistadas, la DGAIA puede decidir a la luz de lo que está pasando, o bien la acogida de un familiar que se pueda encontrar en España, o bien enviarlo a un centro de acogida $\mathrm{o}$ a un centro de emergencia. Ambos suelen estar saturados. Fue referido que intervención especifica, especializada para el caso de trata con fines de explotación sexual no hay. Más bien, para estos menores se favorece el retorno a sus países. Explicaba que ésta es la recomendación y es lo que está pasando.

Sin embargo, cuando hay plaza en un centro de acogida, fue nombrada la falta de preparación de dichos centros para casos de menores tratados.

Finalmente, a nivel de la intervención con menores tratados una de las entrevistadas resumió claramente las dificultades, que residen en el hecho de que se está actuando con los mecanismos existentes, adaptándolos, porque no existen mecanismos específicos para actuar en la problemática.

\subsection{Coordinación de entidades}

En relación a la existencia o no de coordinación entre las diferentes entidades cuya labor se cruza en el fenómeno de la trata de personas con fines de explotación 


\section{perifèria \\ Número 16, junio 2012 \\ revistes.uab.cat/periferia - www.periferia.name}

sexual, es curioso verificar la existencia de algunas opiniones dispares.

Básicamente, los profesionales fueron cuestionados sobre su percepción de la existencia o no de coordinación entre las diferentes entidades. Es interesante constatar que los puntos de vista se dividen básicamente entre la coordinación entre la policía y las ONG.

En relación al trabajo de las ONG más de uno apuntaba como plataforma de coordinación entre las entidades sociales la Xarxa Catalana Contra la Trata de Personas. Sin embargo, parece importante cuestionar si esta plataforma asegura la coordinación entre las diferentes entidades. Los relatos de los que participan nos dan la idea que todavía hay mucho trabajo por hacer, desde estrategias para definir la autonomía y las competencias reales y efectivas.

Además existen las Reuniones de la Taula Técnica del Pla per L'abordatge Integral del Treball Sexual lideradas por el servicio asistencial ABITS (Agencia para el Abordaje Integral del Trabajo Sexual) ${ }^{7}$ y existe otro grupo de trabajo sobre prostitución entre Barcelona y Girona. Estas reuniones y grupos de trabajo son intentos de intercambiar informaciones y transformar metodologías. Esto demuestra el esfuerzo por lograr la coordinación entre las diferentes entidades. Sin embargo, de la asistencia a un par de reuniones he podido constatar que el grado de implicación no es igualitario entre todas las entidades participantes. También me atrevería a afirmar que estas oportunidades de unión de profesionales podrían ser más aprovechadas para definir estrategias de intervención y definición de responsabilidades. Sin embargo, es importante dar el mérito a las entidades sociales que han dado el impulso a estas iniciativas.

\section{Coordinación entre entidades sociales y policía}

Otro tema que ha sido muy mencionado fue la coordinación, o mejor dicho, división entre entidades públicas y privadas. En particular, la relación establecida entre entidades sociales y policía. Aquí las opiniones no son unánimes. Analizando los discursos de diferentes profesionales de diferentes entidades sociales se puede concluir que unos entienden que hay coordinación con la policía y otros no. De lo

\footnotetext{
${ }^{7}$ La Agencia para el Abordaje Integral del Trabajo Sexual es el primer equipamiento público municipal creado para atender de manera específica a las trabajadoras sexuales.
} 


\section{perifèria \\ Número 16, junio 2012 \\ revistes.uab.cat/periferia - www.periferia.name}

observado, parece que la relación establecida entre la policía con las entidades sociales difiere. También es posible justificar esta discrepancia según el lugar que determinado profesional ocupa en cada entidad; es decir, la percepción de una educadora social es diferente de la de un coordinador de proyectos o de una mediadora intercultural. El nivel de interacción con la policía cambia. ¿Además, con quién interactúan? No siempre con los profesionales policiales que trabajan directamente con el fenómeno de la trata sino con cualquier otro policía.

Por otro lado, también se puede entender que si realmente existiera coordinación entre las entidades sociales y los cuerpos policiales, no tendrían por qué existir los condicionantes referidos por los entrevistados.

Es relevante también analizar la posición del inspector policial que reconoce como problemática la falta de sensibilización y/o cooperación de las distintas instituciones públicas o privadas (policiales, judiciales, funcionarios de las distintas Administraciones, personal consular, personal sanitario, intérpretes...).

Las entidades sociales nombraron consecutivamente la importancia del trabajo en red y de la colaboración con la policía. Destacaban también, la importancia de que las mujeres que ejercen la prostitución (posibles víctimas de trata con fines de explotación sexual) no tengan conocimiento de esta relación de colaboración.

En este punto sería importante reflexionar sobre el miedo que las mujeres posibles víctimas de trata tienen de la policía. Sabemos que muchas vienen de contextos sociales en que la policía es el último recurso a quien recurren por su fama de corrupta y abusiva. Sin embargo, una vez que estamos hablando de España, en este caso de Barcelona, ¿no sería importante encontrar una forma de anunciar y establecer una relación de confianza entre la policía y las víctimas?

Está claro que esto solamente será posible cuando las víctimas tengan la posibilidad real de confiar en los cuerpos de seguridad nacionales. Difícil trabajo será éste, una vez que la Ley del Testigo Protegido, que es a la que se acogen los servicios policiales para proteger la víctima, no asegura cualquier protección física. Por otro lado, las víctimas deberían tener claro que no van a ser expulsadas por su situación ilegal en España. Sería un paso adelante conseguir que las víctimas remplacen el 


\section{perifèria}

Número 16, junio 2012

revistes.uab.cat/periferia - www.periferia.name

miedo a la policía por la confianza.

\subsection{Recursos Humanos y Materiales}

En relación a los recursos humanos y materiales las opiniones son unánimes cuanto a su insuficiencia. De recursos humanos existen principalmente los profesionales que trabajan en las entidades sociales prestando asistencia y los profesionales policiales para el proceso judicial. Los recursos materiales son provenientes de subvenciones públicas. El propio Plan Integral de Lucha Contra la Trata ha adjudicado 44 millones de euros para su ejecución. Sin embargo, no hay conocimiento de la evaluación de la eficacia de las medidas implementadas y de la gestión de los recursos. Cuestionando a los profesionales sobre su percepción en relación a los recursos nombraron las siguientes lagunas:

- No hay recursos oficiales de la Administración pública.

- Los procesos de recuperación y rehabilitación de las víctimas son a medio largo plazo y no existen recursos para acompañar este proceso.

- En Cataluña solamente existe un recurso de segundo nivel, de servicio residencial y acompañamiento en el proceso de recuperación. Se ha relatado la dificultad de que este recurso único se adapte a la especificidad de cada caso.

"El punto clave es gestionar efectivamente los recursos." 8

\subsection{Políticas gubernamentales}

Otro de los puntos de vista de los entrevistados interesante de conocer fue sobre su percepción en relación a las políticas gubernamentales. En particular, se direccionaron las opiniones sobre el Plan Integral de Lucha Contra la Trata de Seres Humanos con Fines de Explotación Sexual.

La visión general emanada es que este Plan existe a nivel teórico pero sin aplicabilidad práctica. Tampoco se ha notado un conocimiento extremo del mismo.

8 Entrevista semidirigida no 10 realizada el 10-05-11 


\section{perifèria}

Número 16, junio 2012

revistes.uab.cat/periferia - www.periferia.name

La percepción en general es que es algo lejano. Los que trabajan diariamente en la intervención no lo consideran una herramienta de aplicación válida, pues no tiene medidas concretas de intervención no teniendo una repercusión en su día a día de trabajo.

En relación a la estructura del Plan y a su creación también fueron mencionadas algunas críticas: por falta de involucración de expertos conocedores del fenómeno y por su falta de aplicabilidad práctica.

Es clara la sintonía de opiniones en relación a la creación y ejecución del Plan. Parece que está muy allá de lo que realmente los profesionales necesitan para intervenir. También en relación a los menores tratados hay concordancia con esta visión.

Finalmente, fue referida la responsabilidad de los gobiernos y de las políticas públicas para minimizar los efectos de la trata y su omisión en la problemática. El tema de la responsabilidad es crucial y como nos explica uno de los entrevistados de una ONG no es solamente política. Es social, internacional e individual:

"La trata es la traducción de un fracaso social." $"$ 


\section{perifèria}

Número 16, junio 2012

revistes.uab.cat/periferia - www.periferia.name

\section{Conclusiones y Recomendaciones}

En este texto mostré cómo las perspectivas de los que están en la primera línea de contacto con el fenómeno de la trata de personas con fines de explotación sexual son fundamentales para la comprensión del fenómeno y reflexión sobre medidas de actuación e intervención. Son muchos los problemas y dificultades nombradas. Enseguida, presento algunas soluciones propuestas por estos informantes clave y esquematizo las vertientes de actuación en el fenómeno:

\section{TRATA DE PERSONAS CON FINES DE EXPLOTACIÓN SEXUAL}
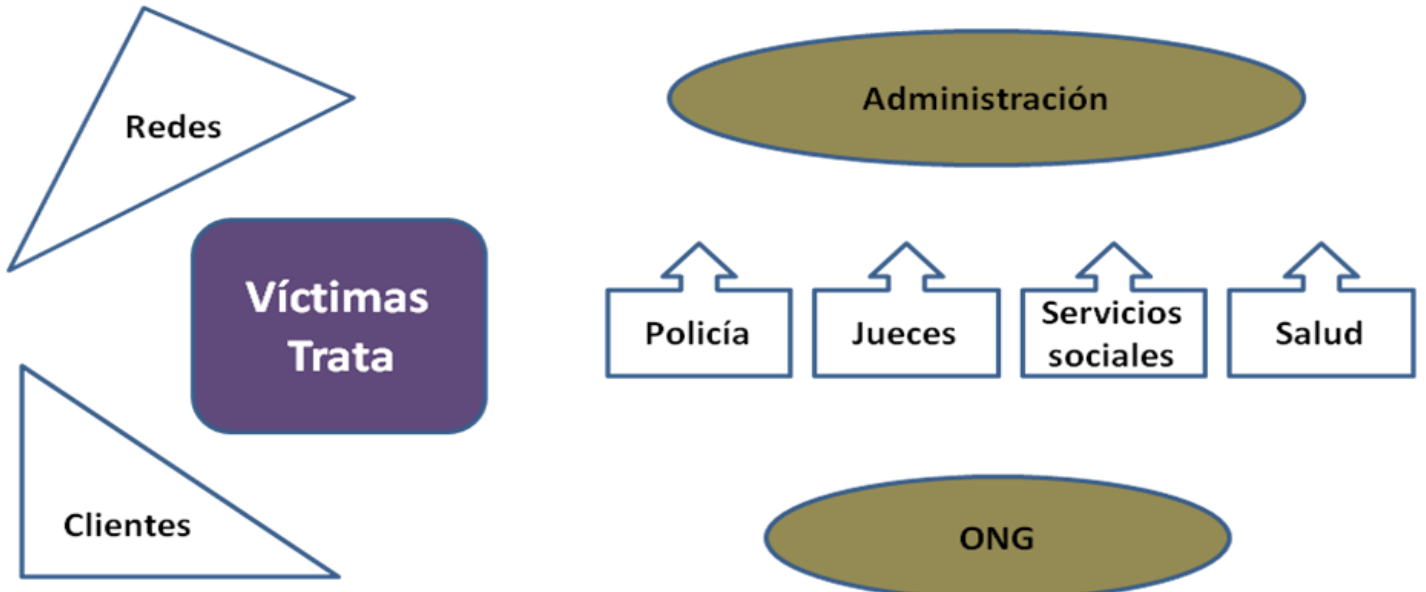

Fig. 3. Esquema de intervinientes en la trata de personas con fines de explotación sexual. Elaboración probia.

A nivel de las víctimas de trata con fines de explotación sexual: fue nombrado por muchos que éstas no se reconocen como víctimas. Tal vez falte sensibilización a las personas que ejercen la prostitución, posibles víctimas de trata, en relación a sus derechos, apoyos y recursos existentes.

"Yo creo que es esencial una buena acogida a estas mujeres, y nosotras cuando las acogemos siempre intentamos pasar el mensaje para que entiendan que al estar aquí y al estar en una situación regular, 


\section{perifèria}

Número 16, junio 2012

revistes.uab.cat/periferia - www.periferia.name

principalmente, porque tienen más derechos los regulares, tienen los mismos derechos como cualquier persona de aquí. No tienen que pensar que por ser de otra cultura, hablar otro idioma, ser de otro color de piel o ejercer el trabajo sexual tienen menos derechos, tal como tienen deberes, pero es importante que lo tengan claro y que tengan claro que los servicios que existen son para todos y no tienen que autoexcluirse. ${ }^{\prime 10}$

A nivel de la Administración y políticas gubernamentales: está claro que lo más reclamado es la ausencia de una real implicación. Todos reclamaban que la problemática de la trata sea una prioridad en las agendas gubernamentales. También fue demarcada la presencia de expertos y profesionales que intervienen diariamente con el fenómeno en la creación de leyes y medidas reglamentarias además de la homogeneización de las mismas.

Otra de las soluciones propuestas a nivel administrativo es que la denuncia no sea tan central, que se creen otras posibilidades y alternativas a la denuncia obligatoria por parte de la persona víctima de trata.

A nivel de políticas gubernamentales y apoyos del Estado fue sugerida la aportación económica a las víctimas para que las mismas decidan su proceso de reconstrucción y rehabilitación, o como mínimo otras formas alternativas pero que permitan esos procesos.

También fue nombrada la legalización de la prostitución como solución a la trata. La falta de recursos como problema fue relatada varias veces.

Por último, hay la advertencia sobre cómo las decisiones administrativas y políticas pueden ser la causa de injusticias sociales.

"Tener una visión más global. Hasta qué punto todo esto tiene que ser competencia de una comunidad autónoma. Yo creo que es ya una cuestión de Estado. Es muy denigrante tener una visión tan gestora de esta realidad pero se está traduciendo en esto. Hay que dar enfoque a derechos humanos pero si lo conectamos con cuestión de género dejamos aparte a los hombres que

10 Entrevista semidirigida no 3 realizada el 14-04-11 


\section{perifèria}

Número 16, junio 2012

revistes.uab.cat/periferia - www.periferia.name

están Ilegando que también están siendo explotados. Este tema no puede ser tan parcelado. Aquí se producen desniveles. ¿Cómo puede ser que tenga una mejor respuesta una comunidad autónoma que otra? No puede depender de la voluntad política, tiene que haber unos mínimos que garanticen que todo mundo va a tener los mismos mínimos. Me parece vergonzoso." ${ }^{11}$

A nivel de las entidades que intervienen en el fenómeno: lo más comentado fue la falta de sensibilización y formación de los profesionales implicados para mejorar tanto los niveles de identificación de posibles casos de trata como los niveles de actuación.

"Primero hay que identificar todos los agentes que podrían tener que ver con la problemática para determinar niveles de responsabilidad en esta detección. Y luego poner en marcha una estrategia de prevención y sensibilización. Porque así aflorarán casos de detección. No pueden ser acciones aisladas. A nivel de protección hay que adaptar y adecuar a la realidad de la problemática de estos chavales tratados."12

A nivel de la sociedad: lo que más fue apuntado por los profesionales es la falta de sensibilización de la sociedad en general. Con la realización de sensibilizaciones eficaces se podría deconstruir estigmas y estereotipos asociados a la prostitución y dar a conocer el fenómeno de la trata y la respectiva responsabilidad social.

"Deberíamos construir espacios en los cuales explicar a la gente qué es lo que realmente pasa en la industria prostitucional. Describir con fealdad y precisión los entornos. Hay mucha tolerancia porque hay una cultura hegemónica del machismo, en todas las sociedades centro-europeas, de que los cuerpos se pueden comprar, forma parte de mercancías que se encuentran en el supermercado. Parece normal."13

\footnotetext{
${ }^{11}$ Entrevista semidirigida no 6 realizada el 28-04-11

12 Entrevista semidirigida no 2 realizada el 13-04-11

${ }^{13}$ Entrevista semidirigida no 10 realizada el 10-05-11
} 


\section{perifèria \\ Número 16, junio 2012 \\ revistes.uab.cat/periferia - www.periferia.name}

"Falta una concienciación social global."14

\section{Referencias bibliográficas}

Agustín, Laura. (2001) Mujeres migrantes ocupadas en servicios sexuales. En Mujer, inmigración y trabajo, Colectivo Ioé. Madrid: IMSERSO, 533-583.

Agustín, Laura. (2006) Atreverse a cruzar fronteras: migrantes como protagonistas. Revista Viento Sur no 87, 73-82.

Ary, Thalita. (2009) O trafico de pessoas em tres dimensoes. Brasilia. Universidade de Brasilia. Instituto de relaçoes Internacionais. Tesis de Master. Publicado en Divulgação Científica em Relações Internacionais.

Auserer, Caroline. (2007) "Controle em nome da proteção":análise crítica dos discursos sobre o tráfico internacional de pessoas. Rio de Janeiro. Pontificia Universidade Catolica do Rio de Janeiro. Tesis de Master. Publicado por PUC-Rio Certificaçao digital no 05107/06/CA.

Doezema, Jo. (2004) !A crecer! La infantilización de las mujeres en los debates sobre «trafico de mujeres». In: Raquel Osborne (Ed.) Trabajadoras del sexo. Derechos migraciones y tráfico en el siglo XXI. Barcelona: Ediciones Bellaterra.

Favaro, Luciano M. (2008) Globalização e transnacionalidade do crime. [En línea] publicado nos Anais do XVII Congresso Nacional do CONPEDI http://scholar.google.es/scholar?hl=es\&q=luciano+monti+favaro\&btnG=Bu scar\&lr=\&as ylo=\&as vis=0 [Consulta, 12 de enero de 2011].

Giddens, Anthony. (2000) Un mundo desbocado. Los efectos de la globalización en nuestras vidas. México: Taurus.

Juliano, Dolores. (2004) El peso de la discriminación: debates teóricos y fundamentaciones. In: Raquel Osborne (Ed.) Trabajadoras del sexo. Derechos migraciones y tráfico em el siglo XXI. Barcelona: Ediciones Bellaterra.

Kempadoo, Kamala. (2005) Mudando o debate sobre o tráfico de mulheres, Cadernos Pagu 25, pp. 55-78.

Maqueda, María Luisa (2007): ¿Es la estrategia penal una solución a la violencia contra las mujeres? Algunas respuestas desde un discurso feminista crítico, en InDRET Revista para el análisis del derecho Indret 4/2007 p1-43.

Osborne, Raquel. (2004) Trabajador@s del sexo: derechos, migraciones y tráfico en el siglo XXI. Barcelona: Edicions Bellaterra.

Osborne, Raquel. (2009) "Construcción de la víctima, destrucción del sujeto: el caso de la violencia de género". Jornadas Feministas de Granada, 5-8 diciembre 2009. [En línea] http://www.pensamientocritico.org/raqosb0210.html [Consulta, 26 de enero de 2011].

Piscitelli, Adriana. (2006) "Sujeição ou subversão? migrantes brasileiras na indústria do sexo na Espanha", Universidade Federal de Uberlândia. N035, 1

\footnotetext{
${ }^{14}$ Entrevista semidirigida no 9 realizada el 09-05-11
} 


\section{perifèria}

Número 16, junio 2012

revistes.uab.cat/periferia - www.periferia.name

Agosto-Dezembro de 2006, http://www.historiaperspectivas.inhis.ufu.br [Consulta, 10 de Diciembre de 2010].

Rubin, Gayle. (1996) El tráfico de mujeres: Notas sobre la "economía política" del sexo. En: Lamas Marta Compiladora. El género: la construcción cultural de la diferencia sexual. PUEG, México. 35-96p.

Santos, Boaventura Sousa. (1999) Reinventando a Democracia, Coimbra: Gradiva Publicações, Fund. Mario Soares, Cadernos democráticos N04, 1999.

Santos, Boaventura Sousa. (2009) Tráfico sexual de mulheres: Representações sobre ilegalidade e vitimação. Revista Critica de Ciências Sociais 87, pág. 69-94

Sassen, Sasken. (2002) Las contrageografías de la globalización: La feminización de la supervivencia [En línea] Biblioteca Virtual de Ciencias Sociales. www.cholonautas.edu.pe [Consulta, 5 de Enero de 2011].

Stolcke, Verena (2000). ? Es el sexo para el género lo que la raza para la etnicidad... y la naturaleza para la sociedad? En Política y Cultura $n^{\circ} 14$, Universidad Autónoma Metropolitana - Xochimilco, p25-60. 